\title{
Striving to Obtain a School-Work-Life Balance: The Full-Time Doctoral Student
}

\author{
Edna Martinez, Chinasa Ordu, Matthew R. Della Sala, \\ and Adam McFarlane \\ Clemson University, Clemson, SC, USA
}

\author{
edna@clemson.edu; cordu@clemson.edu; \\ mdella@clemson.edu; armcfar@clemson.edu
}

\begin{abstract}
The purpose of this study was to explore the doctoral student experience in relation to their school-work-lives. Through a grounded theory research design we sought to explore the following research question: How, and to what extent, do full-time doctoral students strive to obtain school-work-life balance? Data were collected through semi-structured interviews and participant observations with five full-time doctoral education students who held one or more graduate assistantships on campus. From the data, we constructed four themes. Full-time doctoral students strived to achieve a school-work-life balance by (a) purposefully managing their time, priorities, and roles and responsibilities; (b) seeking well-being by managing stress levels, maintaining their mental and physical health, and creating personal time; (c) finding support from various individuals and their institution; and (d) making tradeoffs. Additionally, we found that single students with no children faced more challenges in efforts to obtain a school-work-life balance in comparison to their peers with families. Based on our findings, programs can facilitate degree attainment for students by continuing to provide financial support, flexibility in school and work schedules, and support services tailored to specifically address doctoral student needs. Lastly, our participants' stories may resonate with other doctoral students, and thus, may help them think about ways to attempt to balance their work and personal lives.
\end{abstract}

Keywords: doctoral students, doctoral student school-work-life balance, doctoral student attrition, grounded theory

\section{Introduction}

Doctoral level education in the United States is considered to carry significant public and private benefits. For example, as students reap social and financial rewards associated with their degrees, which utlimately extend beyond the individual (Baum, Ma, \& Payea, 2010), doctoral degree production enables the country to remain globally competitive (Wendler et al., 2010).

Material published as part of this publication, either on-line or in print, is copyrighted by the Informing Science Institute. Permission to make digital or paper copy of part or all of these works for personal or classroom use is granted without fee provided that the copies are not made or distributed for profit or commercial advantage AND that copies 1) bear this notice in full and 2) give the full citation on the first page. It is permissible to abstract these works so long as credit is given. To copy in all other cases or to republish or to post on a server or to redistribute to lists requires specific permission and payment of a fee. Contact Publisher@InformingScience.org to request redistribution permission.
Additionally, doctoral recipients' respective colleges and universities garner prestige (Morphew \& Huisman, 2002; O'Meara, 2007). In terms of doctoral degree production in the United States Wendler et al. (2010) noted:

The US has produced the vast majority of doctoral degrees conferred around the globe. Our graduate schools and their research facilities have been consistently 
ranked among the best in the world (e.g., the Times of London Rankings and the Shanghai Jiao Tong University Rankings), and from 1997 to 2009 over half of the Nobel Prize winners in chemistry, physics, medicine, and economics had received their graduate degrees in the US. (p. 2)

Nevertheless, these achievements are marred by high student attrition rates. Of the number of students enrolled in doctoral programs across U.S. colleges and universities, successful degree completion is unlikely for approximately 50\% (Jairam \& Kahl, 2012; Walker, Golde, Jones, Bueschel, \& Hutchings, 2008). Previous studies centered on doctoral students have identified national attrition rates ranging from 40 to $60 \%$ and varying by field of study (Bair \& Haworth, 2005; Council of Graduate Schools, 2008; Di Pierro, 2007; Walker et al., 2008). Identified as "the central issue in doctoral education in the United States today" (Smallwood, 2004, para. 8), doctoral student attrition has led to a number of concerted efforts to counter student depature (Gardner, 2009). Despite programmatic and institutional efforts to support and retain doctoral students (Di Pierro, 2007; Offerman, 2011), as well as national initiatives such as the Carnegie Initiative on the Doctorate (Walker et al., 2008), national attrition remains high (Jairam \& Kahl, 2012).

Given the consideration of measures that are accepted as predictors of academic outcomes (e.g., test scores) and the degree of screening students undergo prior to admission into a doctoral program, the rate of student attrition is puzzling. As suggested by Golde (2000), "paradoxically, the most academically capable, most academically successful, most stringently evaluated, and most carefully selected students in the entire higher education system - doctoral students - are the least likely to complete their chosen academic goals" (p. 199). Nonetheless, it is important to note that student attrition extends beyond academic issues (Brus, 2006; Offstein, Larson, McNeill, \& Mwale, 2004) and is influenced by multiple factors (Gardner, 2009). According to Gardner (2009) student attrition is "multifaceted" since "...there is no one reason why students leave" (p. 97).

Doctoral student departure has been linked to financial constraints (Kluever, 1997), stress (Lovitts, 2001; Offstein et al., 2004), negative social support (Jairam \& Kahl, 2012), matters of advisor incompatibility (Golde, 1998), isolation (Ali \& Kohun, 2006), and unmet expectations (Golde, 1998). As Hadjioannou, Shelton, Fu, and Dhanarattigannon (2007) maintain "doctoral work is challenging on a variety of levels, stretching often excessively, the minds as well as the emotions, the stamina and the finances of doctoral students" (p. 160). Doctoral education also involves the stretching of time as doctoral students carry various and often competing roles and responsibilities, each demanding time and attention (Brus, 2006; Haynes et al., 2012; Moyer, Salovey, \& Casey-Cannon, 1999; Stimpson \& Filer, 2011). Therefore, as suggested by Brus (2006), doctoral students "struggle to balance their academic pursuits with their personal lives and responsibilities" (p. 31).

Given that a balance between personal and academic components of students' lives has been identified as helpful for successful degree completion (Brus, 2006; Stimpson \& Filer, 2011) and subsequent placement in the academic profession (Brus, 2006), the purpose of this study is to explore full-time doctoral student school-work-lives. Specifically, the following research question guided this study: How, and to what extent do full-time doctoral students strive to obtain a school-work-life balance?

According to Stimpson and Filer (2011), "work-life balance is a topic discussed more frequently in the literature concerning faculty than graduate students in higher education" (p. 70). Consequently, this study contributes to the existing literature by focusing on graduate students' worklives. Further, our study is centered on full-time doctoral education students, which is a minority among education doctoral students (Shulman, Golde, Bueschel, \& Garabedian, 2006) and, there- 
fore, perhaps overlooked in the literature. In addition to the aforementioned contributions, this study generated a working theoretical framework based on participants' experiences and views about school-work-life balance and helped identify support mechanisms that can be implemented in efforts to foster doctoral student success.

Although this study solely focused on doctoral students in the United States (U.S.), doctoral student attrition is not a problem limited to the U.S. In fact, Australia (Bourke, Holbrook, Lovat \& Farley, 2004; Govendir, Ginns, Symons, \& Tammen, 2009), Canada (Berkowitz, 2003), and the United Kingdom (Johnes \& McNabb, 2004) also report significant attrition rates. Thus, this study may contribute to their efforts to retain doctoral students. In the following section we provide a brief review of the literature centered on work-life balance. Subsequently, we discuss the research design and methodology for this study. Last, we present our findings and provide recommendations for practice.

\section{Literature Review}

Attention to issues of work-life balance has been primarily prompted by demographic changes in the workforce (Beauregard \& Henry, 2009; Brus, 2006; Kamenou, 2008). To date, research on work-life balance has been carried out in various contexts including, but not limited to, the medical field (Keeton, Fenner, Johnson, \& Hayward, 2007), construction industry (Watts, 2009), and corporate America (Hobson, Delunas, \& Kesic, 2001). Additionally, and related to this study, work-life balance has been explored in higher education (Bardoel, De Cieri, \& Santos, 2008; Brus, 2006; Byron, 2005; Marshall et al., 2012; Moyer et al., 1999; Rosser, 2004; Sallee, 2008; Stimpson \& Filer, 2011). In academia, work-life has become a topic of import, so much that "over the past decade, work-family balance policies have become a popular [faculty] recruitment tool for research universities" (Sallee, 2008, p. 81). However, although work-life balance has materialized as a topic of study and stimulus for policy initiatives in higher education, few studies have considered doctoral student work-lives.

Similar to the workforce, the doctoral student population has experienced a demographic shift (Brus, 2006; Offerman, 2011). Today's doctoral students are highly nontraditional (Offerman, 2011). For example, they generally exceed 30 years of age and are increasingly female, married, and/or have children (Offerman, 2011). Consequently, the limited literature on doctoral student work-life has primarily focused on women (Brus, 2006; Haynes et al., 2012; Moyer et al., 1999; Stimpson \& Filer, 2011). According to Stimpson and Filer (2011), "balancing work and life is a particularly difficult issue for female graduate students as they face more difficulty balancing family commitments, academics, work, and personal lives, as well as have less satisfaction in their ability to balance work and life" (p. 69). Part of the difficulty for women stems from their role as mothers, often forced to choose one role over the other (Brus, 2006; Stimpson \& Filer, 2011).

Similarly, the female doctoral students in the Haynes et al. (2012) study on their perceptions of well-being experienced conflict between their roles. One participant specifically cited '.... lot of internal battle' (p. 7) in terms of identifying priorities concerning the personal and academic components of her life. Students transitioning from full-time employment to full-time graduate students have also faced issues of balance (McCoy \& Gardner, 2011).

The struggle to balance work and life are sources of stress/pressure for graduate students (Brus, 2006; Mason, Goulden, \& Frasch, 2009; Offstein et al., 2004). Consequently, in addition to compelling students to drop out, the intersection of work and life has led doctoral students to change their professorial aspirations (Mason et al., 2009). Decisions surrounding their personal life have also been influenced by the doctoral journey (Mason et al., 2009). For example, doctoral students often decide to postpone having children (Mason et al., 2009). 
In summation, the preceding discussion has illustrated the context and importance of this study. In the next section, we discuss the research design and methodology which enabled an empirical exploration of full-time doctoral students' attempts to achieve school-work-life balance.

\section{Research Design \& Methodology}

This study sought to understand the full-time doctoral student experience, in relation to both academic and personal components of the doctoral student's life. Given that we were specifically interested in the student perspective, this study is grounded in the interpretivist paradigm (Sipe \& Constable, 1996). As noted by Sipe and Constable (1996) "interpretivists attempt to understand situations from the point of view of those experiencing the situations" (p. 158). Due to the limited knowledge base pertaining to the school-work-life balance of doctoral students, we used a grounded theory research design. The method "consists of systematic inductive guidelines for collecting and analyzing data to build middle-range theoretical frameworks that explain the collected data" (Charmaz, 2000, p. 509). Furthermore, the primary purpose of grounded theory is to systematically discover conditions of a particular phenomenon before determining its conceptual relationships (Glaser \& Strauss, 1967). We postulated that the experiences of doctoral students must be discovered before being understood. Therefore, the grounded theory method was appropriate to answer the research question.

\section{Data Collection}

Data were collected through semi-structured interviews and participant observations. Semistructured interviews were conducted one-on-one and in-person with each participant to gain an understanding of their school-work-life balance. The "school" component was added to the worklife balance equation given that our participants were both students and employees (i.e., graduate assistants) and each role carried differing responsibilities.

In previous studies, "work" has been defined as "paid employment" (Drago \& Kashian, 2003, p. 488). "Life" has referred to "everything outside of work" (Bardoel et al., 2008, p. 317). For purposes of this study, school entailed course work, research requirements, and socialization activities students engaged in such as participating in professional conferences (Weidman \& Stein, 2003) and committee work (Austin, 2002). Work consisted of a variety of financially rewarded responsibilities associated with their assistantship(s) on campus. Student work responsibilities differed based on their assigned faculty members' research efforts and ongoing projects. Lastly, life encompassed the non-academic, personal components of student lives such as family and pastimes or as defined by Bardoel et al. (2008) "everything outside of work" (p. 317).

We selected a semi-structured interview approach in efforts to gather insights and stories from participants, not to impose on them. As noted by Alvesson (2011), semi-structured interviews "...means that there are themes to be covered, but in a relatively broad and flexible way" (p. 53). Interviews lasted between 30-45 minutes, were digitally audio recorded, and transcribed in their entirety. All but one of our interviews took place on campus. Questions centered on our participants' experience as full-time doctoral students. For example, we asked participants to describe what their typical day looked like, what they would identify as their greatest challenge thus far as full-time doctoral students, and what their role as a doctoral student entailed. Additionally, they were asked about other roles they fulfilled and how they balanced them. At the end of all interviews, participants were asked if there was anything else they would like to add.

The majority of our observations also took place on campus and helped us "...understand the research setting, its participants, and their behavior" (Glesne, 2005, p. 51). We made observations for a week as students worked in their offices and went to class. In one instance, one of the researchers joined a participant during his lunch break, along with other education doctoral stu- 
dents. As participant observers, we followed the participant observation process described by Glesne (2005). As recommended by Glesne (2005), “... we carefully observe[d], systematically experience[d], and consciously record[ed] in detail many aspects of the situation" (p. 52). All observations were recorded in a field notebook (Glesne, 2005). Although observations primarily took place on campus, giving us a view into our participants' school and work components, students' lives often accompanied them to campus. For example, we often saw some of our participants' children on campus, providing us a view into their life.

\section{Research Setting \& Participants}

For this study, individuals were selected using purposive sampling. Thus, as noted by Patton (1990), we targeted a particular group of participants due to an identifiable or known characteristic. Specifically, we identified and selected five full-time doctoral students enrolled in $\mathrm{PhD}$ education programs with one or more academic graduate assistantships. Graduate assistantships are employment opportunities for students as they progress toward their academic degree. Students with assistantships are typically appointed within their program of study to support faculty with teaching and/or research responsibilities. Accordingly, assistantships also provide students with professional growth and development opportunities.

Consistent with the literature on doctoral education students, our participants previously held professional positions (Shulman et al., 2006) within the P-20 education continuum. As noted by Shulman et al. (2006), "education students differ from those in the arts and sciences or engineering in that most education students have had careers before pursuing the doctorate" (p. 26). Their full-time status, however, differentiated them from the majority of doctoral education students. As noted by Shulman et al. (2006) "in contrast to other doctoral students, the majority of education doctoral students attend school part-time while continuing to work" (p. 26).

All students were enrolled at Bustle University. Bustle University (BU) is a large southeastern university classified by the Carnegie Classification as a research university with high research activity. We point to Bustle's Carnegie Classification, as it is a reflection of faculty work at BU and therefore that of our participants. As noted by Austin (2002), "the research mission of the American university depends in part upon the work of graduate students who serve as research assistants for professors" (p. 95). Below we provide a brief biography for each of our participants. All names in this study are pseudonyms.

Cindy. Cindy is a first year, second semester, full-time doctoral student. She currently holds a graduate assistantship where she is responsible for carrying out a variety of tasks. Some of these tasks include preparing, planning, and organizing for an academic conference as well as heading up an organization to initiate success for college students. Although Cindy's assistantship requires 20 hours of work per week, she often feels as though she is working full-time "because the load can be a lot." Cindy is single and lives with her younger brother who is enrolled as an undergraduate student at another institution.

Lisa. Lisa is a second year, full-time student in her doctoral program. She currently holds two assistantships in which she does extensive research, presentations, and site visits. Lisa opted to take on an additional assistantship for financial reasons and currently works 30 hours a week. Additionally, she is a married mother of three children.

Thomas. Thomas is a second year, full-time doctoral student. Similar to Lisa, he has two assistantships in which he conducts research and gives presentations. Furthermore, he teaches an upper level undergraduate course related to his major. He is a husband and a father of one child. Thomas and his wife are currently expecting their second child. 
Tina. Tina is a second year, full-time doctoral student. Also working two assistantships, she dedicates 10 hours a week to one professor and 20 hours a week to another. Her assistantships involve research related tasks. Tina also serves on an advisory committee to the dean and sits on a faculty search committee. Tina is a single mother of one and also provides care for a parent. Additionally, Tina faces an hour and a half commute to campus, each way.

Willie. Willie is a second year, full-time doctoral student. In addition to his position as a research assistant, Willie serves as the collegiate advisor for a fraternity. Unlike a number of his peers, Willie is single and does not have children. Furthermore, he has no family in the area. To this end, he spends most of his time on campus and notes that his situation is perhaps less demanding than his married counterparts with children.

\section{Data Analysis}

In order to discover and understand the experiences of doctoral students related to their schoolwork-life balance, data was analyzed using the constant-comparative method (Glaser, 1965). As maintained by Glaser and Strauss (1967), the purpose of constant-comparative analyses is to generate theory in a systematic manner. Grounded theory methods utilize highly organized and detailed procedures. For instance, coding and memo writing occurs at various stages of the research process in order to construct complex concepts. Themes and concepts are identified from the data and consistently compared to all other data sources in the research study. These comparisons tend to lead to denser and more precise categories and propositions; comparisons stop at the point when categories become theoretically saturated (Charmaz, 2000; Glaser \& Strauss, 1967; Merriam, 1998).

For this study, we started by individually reading all transcripts and observation notes for conceptual meaning. Second, open coding was conducted on interview transcripts to identify concepts (Glaser \& Strauss, 1967). As a group, axial coding was used to make connections between categories and their subcategories, reducing the number of concepts into discrete themes (Charmaz, 2000). Through constant comparisons and axial coding, we analyzed, reduced, and categorized concepts based on shared meanings. The recoding and regrouping into discrete themes allowed us to clearly analyze the relationships and effects between the identified themes. Finally, notes from observations were used to confirm or refute findings from the analysis. The constant comparative method helped increase the internal validity of our findings (Boeije, 2002).

Two methods were used to represent and systematically summarize the findings of the study. First, quotations from interview transcriptions and details from observations notes were selected to demonstrate participants' expressed thoughts and detail the complexity of the phenomenon. Indeed, the use of primary data is necessary in qualitative research because it strengthens the validity of the study (Wolcott, 1990). Second, findings from the analysis were represented in a figure (see Figure 1on page 54) to illustrate the grounded theory and explain how doctoral students strive to achieve a school-work-life balance.

\section{Findings}

As full-time doctoral students on assistantships, our participants' experiences were shaped by (1) school, (2) work, and (3) life. As previously indicated, school entailed course work, research requirements, and socialization activities our participants engaged in. Work consisted of a variety of financially rewarded responsibilities associated with their assistantship(s) on campus. Lastly, life encompassed the non-academic, personal components of student lives. In efforts to attain a balance between these three dimensions, participants revealed that they (a) purposefully managed their time, priorities, and roles and responsibilities; (b) sought well-being by managing stress levels, maintaining their mental and physical health, and creating personal time; (c) found financial 
and emotional support from various individuals and student services; and (d) made tradeoffs. In the following subsections we present these findings supported by numerous data points.

\section{Purposeful Management}

Participants purposefully managed factors that were influential in their efforts to obtain a schoolwork-life balance. Specifically, they worked to manage their time, priorities, and roles and responsibilities. Purposefully managing these facets was particularly important because, although our participants were full-time students working "part-time," it often seemed otherwise. For example, when discussing her work responsibilities, Tina suggested "it's a seven-day-a-week job." Similarly, Cindy noted:

... even though you know you're only working part-time, I feel like I'm working fulltime because the load can be a lot. But you just make the time; set a plan, there's definitely a balance between work, school, and helping family, even though my brother is an adult himself. It's really just about time and planning.

In addition to feelings of working full-time, given that each day was different, participants had to further manage these facets. For example, when asked about what her typical day looked like, Lisa began by discussing her family's morning routine, but shortly concluded "there's no real typical day."

I have to say that there's no real typical day. It's hard to say. But if there is, if I'm not traveling, if I'm not doing data collection that's off site...then usually [I'm] working on deadlines for conference proposals, drafting conference proposals, writing, finishing a book chapter, and finishing a manuscript that was due for submission.

Having set up the context in which these full-time doctoral students find themselves, in the following sections we present how participants strived to obtain a school-work-life balance by managing time, priorities, and roles and responsibilities.

\section{Managing time}

As suggested by our participants, time is an integral component to school-work-life balance, particularly because as time is allocated to one domain, less time is allocated to another. As suggested by Lisa, embarking on a $\mathrm{PhD}$ means having to "balance your time differently." Although no day is typical, our participants tried to maintain some type of normalcy to their daily schedules. Thomas spoke of the importance of managing his time, drawing attention to the fact that his family-life and his work-life are structured into specific timeframes throughout his day. Thomas explained:

I usually drop my daughter off at school and get here around 8:00 a.m., maybe 8:15 and I try to keep up with class readings and I'm teaching a course so I'm trying to keep up with plans and grading. My schedule is pretty flexible. I have one course where I meet on Monday evenings around 5:00 p.m. and then I teach my course on Tuesdays and Thursdays from 11:00 to 12:15. Usually mornings are pretty crammed. I try to get as much done as possible. I go to lunch with friends, other doc students for about an hour or so. Then I come back and work on papers or try to get stuff done for my research assistantships for my professors. So basically from 8:00 to 12:00, really busy, then lunch, then come back and from 12:00 to 5:00 really busy.

All students alluded to the fact that how they manage their time is imperative to balancing numerous tasks, whether school, work, or life related. However, although participants acknowledged the value of time, consistent with previous studies on doctoral students, they struggled with time management (McAlpine, Jazvac-Martek, \& Hopwood, 2009; McCoy \& Gardner, 2011). 
When asked about their greatest challenge as doctoral students, 4 out of 5 participants cited time management. Although they made concerted efforts to manage their time, they still found themselves running out of time, working till the last minute, or, as Tina said, at "the $11^{\text {th }}$ hour." Of this she said:

I've had to really learn how to manage my time better and I'm still having to learn because I'm still not as good as I'd like to be, I'm still finding myself at the $11^{\text {th }}$ hour doing things that I really wish were not being done at the last minute. I think part of that comes with wisdom of learning when to say no. I guess maybe early on though, I feel if I'm really asked to do something, I'm going to jump at the opportunity because that's the only way I'm going to know if that's something for me in the future or not. So I guess the biggest challenge for me has been juggling so many things without dropping one of those precious little balls. Fortunately, when I have occasionally dropped one, it has bounced back up, they don't fall and break, but that's been the most difficult thing, is time management

Willie also expressed similar sentiments in terms of time management. He shared his experience of this "greatest challenge" as follows:

The greatest challenge [has been] time management, we all hear that in whatever you do. It's like time management, you've got to structure your time, but here it's like the importance of getting your schoolwork done because that's why we're here, but then you're working with your professor and they have projects going on, but then on top of that you want to get your own stuff out there, and try to go to conferences and present and try to work with your advisor, plus what you have to do for your assistantship in addition to like your own personal projects that you're trying to get out, it becomes like a challenge cause everything is pressing, everything has a major deadline, everything needs to get done, so after a while you just become like "oh my God I got to get this done." But, learning to structure that time and being like "ok I can devote like a couple hours to this and then do that."

Given that "everything is pressing, everything has a major deadline, everything needs to get done," our participants found it necessary to prioritize. This finding is discussed below.

\section{Managing priorities}

As previously specified, for our participants no two days were the same. Therefore, priorities were managed on a day to day basis. As stated by Tina, "everything comes down to a day-by-day, issue-by-issue determination of what is most important at this moment in time." Nevertheless, as acknowledged by Tina, sometimes "the tyranny of the urgent rears its ugly head." When discussing her work responsibilities for two different professors, Tina noted:

I think it is pretty balanced. And I think that unfortunately the tyranny of the urgent rears its ugly head. With a national conference coming up in two weeks, a lot of my focus has been on working with [said professor] in getting ready for the conference, so some of my other work has kind of taken a back seat, but I'm still working on it, it's just not as much of a priority right now. It's a juggling act, and sometimes I touch one of the balls more often than the others when I'm juggling, but they are all still going.

Once students determined what was most important, it required saying "no" to other things. For some students this was particularly hard as they often felt they needed to accept every research, teaching, or service opportunity that presented itself, in efforts to secure a future position in academia. This notion primarily grew out of their socialization experiences (Austin, 2002; Weidman $\&$ Stein, 2003). According to Lisa, “...typically professors will say 'Oh, you know, do you want to help? Are you interested in doing this? You know you can get a publication out of it'. So you 
sign on to do that and the next thing you know you're, it sounds interesting, but you've got 3 or 4 extra projects on top of all your other work."

Lisa, who eagerly accepted almost every opportunity that presented itself during her first year, learned the hard way, especially when personal issues emerged. Therefore, during her second year, she began to manage her priorities more intentionally:

Again it got pretty severe last semester, there was really nothing I could do except keep plugging away [at] what I had to do to get all the things done. It was like nonstop really for the last two months of last semester. And this semester...I'm just not taking on anything else unless it specifically relates to my research area or something I am initiating on my own. I won't be taking on any other projects.

In efforts to achieve all that needed to be accomplished, Thomas was also strategic. Specifically, his "top priority work" was taken care of in the morning. Additionally, he managed his work priorities around his life priorities.

I try to get all of my top priority work while I'm here [at work] and then in the evenings I take a break until my wife and my daughter go to sleep. My wife goes to bed about 9:30 or 10. My daughter goes to bed around 8:30. Then I'll read or do some work on a paper that is not pressing. So I don't try to do any hardcore brainwork in the evenings cause I'm pretty spent.

Willie was very clear on his priorities. Specifically, Willie put school first because he believed everything depended on it:

The first thing is like my schoolwork because if I don't get something in for school or my class then if I get put out of school there's no assistantship, and there's no need to worry about presentations, and conferences because you're not here. There have been certain situations where there were conferences or proposals due, but it was kind of like something personal for me that was extra, but there was a lot of class work that was due so I had to make a choice, it was like do I get this paper done or do I try to do all of this and kind of half-ass a paper, but like for me education is first and I'm here to be a student and so I usually will prioritize that and then comes like obviously the assistantship work and everything else so that's kind of like how it goes.

In addition to prioritizing tasks, students prioritized their roles. Students' life roles (e.g., parent, daughter, spouse) always took precedence over their roles as students and graduate assistants. For example, Tina's identified her daughter as her main priority, accordingly Tina noted, "sometimes you have to put down the doctoral studies to deal with a daughter who is having a rough time with something or whatever." Similarly, Lisa's main priority was her family. Yes, she was concerned about "pleasing" the people she was working for, but ultimately she worked to ensure that her family was "... happy and that everything that needs to get done for them gets done." These examples lead us to our next theme: managing roles and responsibilities.

\section{Managing roles and responsibilities}

As previously noted, graduate students carry various and often competing roles. According to Haynes et al. (2012), "the differing roles of graduate students contribute to and detract from their program fulfillment and life satisfaction" (p. 3). However, our participants whose roles included students, graduate assistants, parents, spouses, caregivers, siblings, and organization advisors, among others roles, worked to counter this dilemma. Specifically, they attempted to manage their multiple roles and responsibilities to work in accord. Tina, for example, has been successful in managing her school and work responsibilities to work in her favor via "purposeful assignment placement." She explains this notion below: 
The courses I'm taking this semester are tying in beautifully to what I'm doing with my research assistantship, in terms of the projects that I am doing. For instance, for my [said] class we have to write a research proposal, and so I am able to do that using data that I am already analyzing for [said professor]. I have to do a literature review for another one of my classes and so I can do that with one of my assistantships because I'm going to be doing a literature review anyway for [him/her], so I don't know if I would call it doubledipping, I would prefer to call it purposeful assignment placement. So they actually balance out nicely.

Tina also frequently attempts to manage her roles and responsibilities as a mother and doctoral student. Although not entirely successful in the following example, in the end, both role obligations were fulfilled:

Last weekend, my daughter had a visit scheduled for a college, my intention was to go work somewhere on the computer while she was doing her tour, when we got there I realized they had all kinds of stuff for me to do too, like financial aid seminars and so forth, so I didn't get any work done on Saturday. But that was okay though since I needed to do that for my daughter on Saturday, so on Sunday, I did my work.

Like Tina, Thomas and Lisa purposefully managed their role and responsibilities as parents, students, and graduate assistants. Thomas, for example, strove to make it home by dinner to spend time with his family and then continued working once his wife and child were asleep.

I usually try to go home to have dinner. Sit down with my wife and my kid. Read to my daughter and spend some time with her on her homework before she goes to bed around $8: 30$. And then I do more reading or work.

Lisa at times was unable to make it home early or in time for dinner, but still dedicated time to her children. As she continued to work, we observed that they joined her on campus. Cindy also managed her roles and responsibilities as a student and graduate assistant in accord with her responsibilities as an older sister. Cindy's brother, who was currently attending school at a nearby college, depended on her for transportation. Cindy explained how she worked to meet her obligations:

...his classes are every day, so Monday/Wednesday/Friday is one class. So those days I drop him off and I'll pick him up, cause his class is only from 9 to 10 a.m. And then I drop him off and go to work, so those days I cut down my work hours. Tuesdays and Thursdays he has class at 8 in the morning so I drop him off, go home, and get ready for work, and then he takes the bus to [Bustle], and we ride home together. If it's a day I have class, it depends. On Tuesdays I can drop him off then come back to campus for class and Wednesdays, he's already at home, so I just stay on campus the rest of the day. So we have a little system going on.

As Cindy and her brother had a system to make sure they both made it to school, our participants had a system to seeking well-being. This theme is discussed in the following section.

\section{Seeking Well-Being}

Evidently, as discussed by our participants, attempting to "juggle so many things" can take a toll on student's well-being. As noted by Haynes et al. (2012), "well-being can be viewed with both a health and a social lens" (p. 2). Our participants specifically spoke of well-being from a health perspective. They noted that a school-work-life balance was imperative to one's well-being. Willie painted a drastic picture of how the lack of a work-life balance can have a negative impact on one's well-being. Of this he said, “... a work-life balance has to exist for your health and your sanity." By the same token students felt that in efforts to achieve a work-life balance they had to 
seek well-being. Consequently, students worked to maintain their health, manage stress, and find some personal time. Each component is discussed below.

\section{Health}

We define health in the context of how doctoral student maintain their sanity, their physical and mental well-being, and any associated coping mechanisms they use as a result. Exercise helped students achieve both physical and mental well-being. By walking in the mornings, Lisa was able to exercise and clear her mind:

I think one of the things my friends and I would, when the weather's nice, we would go walking in the morning. And it's for exercise but I think it also kind of clear our heads and we can talk and just get outside and get fresh air and clear our minds.

Lisa believed that physical activity was crucial to achieve a healthy balance. Our participants found it necessary to engage in similar activities in their efforts to find a balance between school, work, and life. Although exercise helped release stress, our participants employed additional strategies which are discussed below.

\section{Stress}

As much as our participants enjoyed being full-time students, there were a number of pressures related to school, work, and life that resulted in stress. Stress among graduate students is not unheard of (Offstein et al., 2004). As Offstein et al. (2004) suggested, "Stress is at the core of the graduate student experience and is amplified by conflicting demands and internal conflict unique to this type of student" (p. 396). Stress was brought on by deadlines, limited finances, time, family issues, and taking on additional responsibilities that students felt would help position them for an academic position upon graduation.

Perhaps due to their challenges with time management, reaching deadlines was a primary pressure felt by most of our participants. They expressed the stress that accompanies these deadlines as being constricting and diminishing from their overall sense of well-being. In efforts to release stress, participants employed various mechanisms. Cindy noted that in those moments when she gets really stressed, she cries:

When I have my moments, sometimes I cry. I go into my room and cry. I had a couple of [moments].

Whereas Cindy isolated herself and cried, other students managed stress differently. For instance, rather than isolating herself, Lisa incorporated friends:

I love to get unstressed (chuckle). Let me think, just kind of going out with friends sometimes after school, just having a beer or going out for coffee or something like that, those kinds of things too. Talking to friends a lot helps.

After having a beer or coffee, Lisa and her friends, who are also fellow doctoral students, often found themselves going back to work. Other times, however, Lisa took some personal time. This was true of all our participants in their efforts to seek well-being.

\section{Personal time}

Personal time for our participants was especially important. They expressed that personal time was imperative as they strived to maintain well-being. Tina's personal time took place during her long commutes to campus. Additionally, she took some time to herself when she got home. Specifically, she took 30 minutes of isolation in her room to decompress and transition her mind to home life. Tina shared the following: 
I would get home from school and take 30 minutes in my room by myself and my daughter knew that was my decompression time and my transition time.

In the following quote, Lisa describes how she embraces her personal time:

Sometimes just, hanging out with my kids, especially my son who's $8 \ldots$. just watching a

TV show with him, as silly as that sounds can be very relaxing and stress free.

Here Lisa enjoys using her personal time with her children. She takes pleasure in the simple things in life, stating how she enjoys watching a TV show with her eight-year-old son. She characterizes these types of moments as relaxing and stress free. Doctoral students with familial obligations describe their personal time with their family to be paramount to their ability to maintain their well-being.

Willie, who had no family in the area and previously described school as his main priority, spent most of his time in the education building.

Most of my days and nights are spent on campus in [the education building] cause that's where my office is and sometimes I feel like I don't know why I pay rent, but, yes, most of my time is spent here on campus either in [the education building] or the library because my office and all of my classes are also in [the education building] so I pretty much live there.

Despite living in the education building, Willie found time for himself. Of this he said:

I feel like there has to be that thing that puts yourself outside the element of being a PhD student and being a grad assistant and as long as that thing, you're not being a grad assistant, you're not being a student, and your just like taking time out for yourself like that's where that balance comes in. We could all very well do nothing but our school work and worry about presentations and like conferences, but we would probably go crazy and you would never get out of this program because the stress and everything else would probably kill you.

While some participants enjoyed personal time on their own, they recognized that efforts to achieving well-being could not be accomplished alone. Consequently, they sought and found support.

\section{Finding Support}

Doctoral students relied on various support structures as they strived to achieve well-being, and thus, a balance between school, work, and life. Evidently, as suggested by Stimpson and Filer (2011), “... the fact that graduate students have previously navigated that higher education system successfully does not mean that they will not need assistance as they pursue their graduate degrees" (p. 74). Sources of support sought by our participants included formalized institutional support and social support. Each of these support structures are discussed in the following sections.

\section{Formalized institutional support}

As previously cited, "doctoral work is challenging on a variety of levels, stretching often excessively, the minds as well as the emotions, the stamina and the finances of doctoral students" (Hadjioannou et al., 2007, p. 160). This statement spoke to the experience of our participants on different and varying degrees. And while in some instances, students were able to handle these challenges by crying or having a drink, other times they required formalized support. For example, in times of stress related to personal issues, which ultimately started affecting work and 
school, Lisa sought support through the university's counseling services. She realized that in her effort to find a school-work-life balance that she needed to tend to all areas of concern in her life.

Other students found support from their faculty and advisors. Brus (2006) contended that "inflexibility is one of the least recognized or acknowledged constraints on graduate students with dependents" (p. 36). However, participants with dependents in our study praised their faculty for their level of flexibility. Tina, for example, who faced a total commute of three hours to school each day, shared that faculty allowed her to work from home if necessary. Tina took heart knowing that she has a strong support system to help her achieve balance:

My professors are very supportive of me knowing my long drive, knowing I'm a single mom, knowing that I'm taking care of the house and helping my mom and she's helping me and so forth. My colleagues are supportive as well. If I didn't have the support of everybody in the mix, I think it would be a lot more difficult. Perfect, no. But supportive.

Although faculty members have been identified as a form of social support (Jairam \& Kahl, 2012), our participants spoke of faculty as members of the university. Thus their ties were more academic than social.

In addition to finding support from student services and faculty, students found support through financial resources made available through the university and their programs/departments. As previously noted by Tina, "there is no time to work outside of the program, not if you're going to keep your sanity and your health;" therefore, this form of institutional support helped foster their efforts to achieve a school-work-life balance. Thomas described how institutional financial support in terms of his assistantship, reduced tuition fees, and student travel grants has afforded him the opportunity not only to be enrolled, but to enhance his doctoral student experience:

Money is definitely tighter but I found that [Bustle] is pretty helpful with grants. I've applied for three grants for traveling to do research presentations and I've gotten every one of them without a big hassle. That's definitely helpful. Student loans are there. The research assistantship pays 15,000 a year for 20 hours a week and they help with tuition too. I did take out student loans for a couple of summers just so I wouldn't be completely broke, but I don't want to get too far in debt. I'm making less than half of what I made.

As doctoral students are seeking to strike a balance between their work and personal lives, they realized the importance of seeking the support of other people and resources. They understood the importance of seeking support when situations were outside of their locus of control and recognized that the help they received assisted them in their efforts to maintain a balanced life.

\section{Social support}

Doctoral students who are able to receive support from their families and friends are able to move towards a more balanced approach to school, work, and life. Thomas finds solace in the fact that his wife is supportive of his educational pursuits by describing how she understands his desire to enroll full-time and pursue additional scholarly work. Thomas found that the support of his partner has been instrumental in his ability to maintain a balance:

She's been really supportive in all of this. She knew I wasn't overly happy in my career as a middle school teacher. She saw I wasn't excited and how I was with my master's program and how I wanted to keep doing scholarly work. She's really supportive. That first year, when I was teaching and taking pretty much a full class load, that was really tough on our relationship, but she supported me through it and now I learned to balance things and to make time for them. That's really important for me too. I don't just do it for them. 
Tina also found support in her family; she felt very fortunate that both her mother and daughter were very understanding and supportive. Cindy found support through her involvement with a student organization on campus. Lastly, all of our participants found support in fellow doctoral students.

\section{Making Tradeoffs}

As doctoral students strived to achieve a school-work-life balance, various tradeoffs existed. Examples included finances, time with family, and time for self. As previously noted, prior to enrolling in school full-time, all our participants held full-time salaried positions, and although most participants felt as if they were currently working full-time, their income did not amount to such. To this point, Cindy, who was in her first year of study and thus had just recently experienced a significant decrease in income cited a trade-off in finances. Of this she said:

Sometimes I miss working full-time to be able to afford little things like my hair, nails, and other stuff I took advantage of while I was working. I have to budget out everything now so I don't get myself into a super debt. I didn't want to have too much debt.

Tina also cited financial trade-offs. Nonetheless, asserted "I don't really know any doctoral student that hasn't made financial sacrifices, there is no time to work outside of the program, not if you're going to keep your sanity and your health." Tina believed that despite all of the things she was "juggling" she had "... not seen anything suffering in terms of [her] personal life. I still have plenty of time to spend with my daughter, I have my weekends with her, I have my evenings except for the evenings that I have class here, but I still get home at a decent hour."

Conversely, both Thomas and Lisa cited less time with their families as a trade-off. Lisa, for example, stated:

... my life is very busy and if I had my way I would spend more time with my kids and be able to pick up my kids from school and help them with activities but I'm not always able to do that because of my heavy schedule.

Although our participants were full-time students, given the demands placed students by life and work, school was often the tradeoff. Of this, Lisa disappointingly noted:

...it's all the work I have to do for my job to go through the program. I don't feel like I'm getting as much out of my courses as I could if I wasn't working so much. So, um cause I'm thinking I could really study and read this but there no more time to read. So I do what I can, not saying I never ever do it umm, let me think for a second, I'm not saying I don't do it but it's the last thing, it's so, I mean, even with my school work, again projects that I'm on with other people are going to take priority over things that I do for myself because I feel like as part of a team you need to pull your weight and you can't let other people down and so umm, that's kind of the order, the order of operations in the doc life but um I do wish I could work less, so that I could read more, forget, you know beyond my class reading, you know like reading a journal, that's not assigned is not happening right now. And it's really a big shame because I feel like I'm not getting as much as I can out of the program.

In the following sections we discuss our findings, followed by our conclusion and recommendations for practice. 


\section{Discussion}

This study highlights the various ways full-time doctoral students strived to obtain a school-worklife balance. Based on the findings, we discovered that our participants aimed for balance through: (a) purposeful management; (b) well-being; (c) support; and (d) tradeoffs.

Participants in our study acknowledged the importance of school-work-life balance and although not always successful, they were intentional about managing factors they found influential in their attempts to achieve it. Specifically, they managed their time, priorities, and roles and responsibilities. Students acknowledged their challenges with time management, while "juggling" multiple roles and responsibilities. Nonetheless, they worked to improve their practices. They strategized and aligned the responsibilities associated with their different roles to work in concert with each other. Tina, for example, carried out what she termed "purposeful assignment placement." By linking her class and work assignments, she was able to maintain a satisfactory life. As quoted earlier, she had "not seen anything suffering in terms of [her] personal life."

Although this study was not designed to explore differences between students with children/dependents and those without any, we found that single students with no children faced more challenges with time management in comparison to their peers with family. As previously noted, Willie wondered why he even "pa[id] rent" as he spent most of his time on campus. Additionally, although our parents were involved in more projects than our non-parents, non-parents appeared more stressed.

Students' desire for balance also led them to seek well-being by observing their health, reducing stress level, and creating personal time. Exercising, and releasing stress, either by crying or having a drink, helped students continue carrying out their roles and responsibilities.

Although the multiple roles participants carried were sources of stress given the responsibilities that came along, they were also sources of support. As highlighted in our analysis, support from our participants' families helped them in their efforts to maintain balance. Support provided by the institution was also instrumental in helping participants balance school, work, and life. In addition to student services such as counseling and supportive faculty, financial support played a significant role in facilitating a school-work-life balance, especially as working outside of the program was deemed as negatively impactful on one's physical and mental health.

As helpful as the institution was, some participants identified some programmatic practices that obstructed their efforts to achieve school-work-life-balance. Specifically, course offerings challenged some of our participants' efforts for balance. Although "not all doctoral programs welcome part-time students and some faculty may even caution against pursuing a program parttime" (Gardner \& Gopaul, 2012, p. 73), Bustle University's doctoral education programs are welcoming and cater to part-time students, particularly via course offering. As noted by Shulman et al. (2006), "to meet student needs, many education doctoral programs teach the majority of classes in intensive evening or weekend formats" (p. 26). The practice of offering evening courses, although common among education doctoral programs, compelled students to stay on campus all day. Additionally, although thankful for financial resources provided by Bustle, participants highlighted the low wages. As previously noted, some of our participants had taken on an additional assistantship to support themselves financially. The extra assistantship added 10 more work hours to a schedule which already seemed, for some students, to be that of a full-time employee.

Evidently, as students engaged in purposefully managing certain components that impacted their experience, tradeoffs were inevitable. Tradeoffs differed for students based on what they identified as their priorities. Nevertheless, overall our participants were satisfied with their experiences at Bustle University and believed that the sacrifices they were currently making would pay off at the end. At no time during the interview or our observations did participants indicate any inten- 
tions to leave their programs. We attribute this to their efforts to achieve a school-work-life balance.

Figure 1 illustrates a working theoretical framework that emerged from the data analysis. Participants developed structure and sought support in their effort to obtain work-life balance. What was inherent in all participants' perspectives was the need for well-being, including health, stress, and personal time. Indeed, participants expressed that mental and physical health was necessary in order to achieve work-life balance. In the following section we conclude our study and provide recommendations for practice and future research. The recommendations are primarily based on our analysis, but also include recommendations provided directly from the participants based on their experiences.

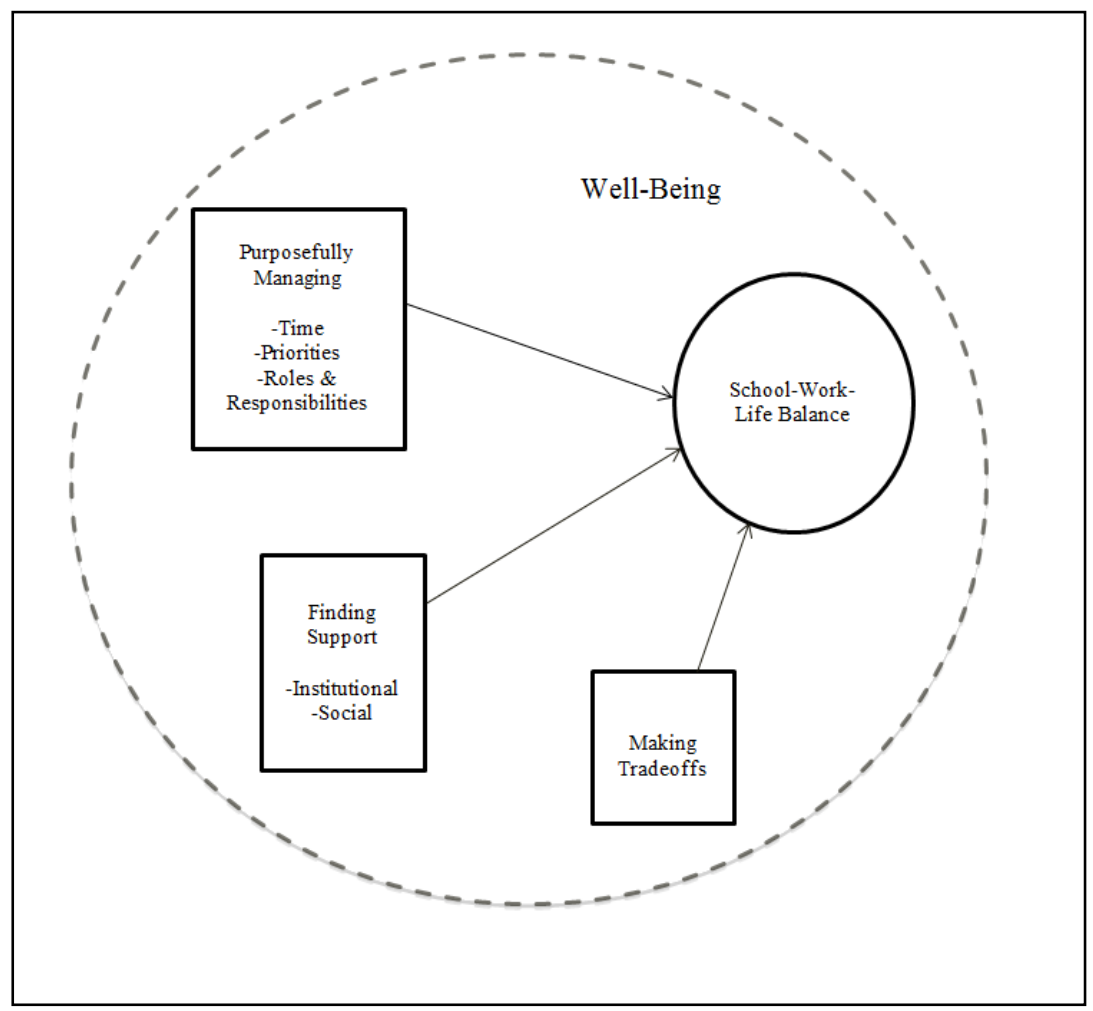

Figure 1: In efforts to obtain school-work-life balance, participants purposefully managed factors influential in their efforts to obtain a school-work-life balance, sought support, and made trade-offs. What was inherent in all participants' perspectives was the need for well-being, including maintaining their health, managing stress, and creating personal time. Indeed, participants expressed that mental and physical health was necessary in order to achieve school-work-life balance.

\section{Conclusion \& Recommendations}

Although work-life balance is a widely researched field (Byron, 2005), few studies have explored the experiences of doctoral students (Stimpson \& Filer, 2011). Bearing in mind the struggle that graduate students often experience in balancing their academic and personal lives (Brus, 2006), this research explored how, and to what extent full-time doctoral students strive to obtain a school-work-life balance.

Based on these findings, we believe programs can facilitate degree completion for students by continuing to provide financial support, flexibility in school and work schedules, and student ser- 
vices tailored to address doctoral student needs. For future and current doctoral students, our findings may help them think about ways to attempt to balance their school, work, and personal lives. Our paper presents the voices of both male and female students; nonetheless, we acknowledge the small number of participants. Consequently, for future research we recommend targeting a greater number of participants.

In light of our participants' experiences, the following recommendations are offered for programs, departments, and institutions committed to supporting school-work-life balance efforts of students, which may ultimately contribute to successful degree completion:

1. More courses offered during the day. Participants discussed the importance of and sacrifices they made to go back to school full-time; however, some expressed that limited departmental course offerings countered their motivations and did not support their efforts to balance their school, work, and life roles and responsibilities. Some participants felt that their position was not taken into consideration when courses were planned. Specifically, they believed that courses catered more to the schedules of part-time students.

2. More financial support. Several participants praised the financial support provided by the institutions, nevertheless, noted the importance of increased financial support both in terms of their assistantships and travel grants. Participants stressed that assuming another job to gain additional income would be counterproductive in their efforts to achieve school-work-life balance. Some of our participants noted that in order to make ends meet, they had taken on a second assistantship, which was currently impacting how they balanced their multiple and often conflicting roles and responsibilities.

3. Provide flexibility. Several participants discussed how the flexibility of their faculty members and their assistantships afforded them with the opportunity to find a balance between school, work, and life. More efforts should be made to build in flexibility in the work and school schedules of students, even allowing them to work from home if the assigned tasks and responsibilities can be completed in those confines.

\section{References}

Ali, A. \& Kohun, F. (2006). Dealing with isolation feelings in IS doctoral programs. International Journal of Doctoral Studies, 1, 21-33. Retrieved from http://ijds.org/Volume1/IJDSv1p021-033Ali13.pdf

Alvesson, M. (2011). Interpreting interviews. Thousand Oaks: Sage.

Austin, A. E. (2002). Preparing the next generation of faculty: Graduate school as socialization to the academic careers. The Journal of Higher Education, 73(1), 94-122.

Bair, C. R., \& Haworth, J. G. (2005). Doctoral student attrition and persistence: A meta-synthesis of research. In J. C. Smart (Ed.), Higher education: Handbook of theory and research, Vol. 19 (pp. 481584). Dordrecht, Netherlands: Kluwer.

Bardoel, E. A., De Cieri, H., \& Santos, C. (2008). A review of work-life research in Australia and New Zealand. Asia Pacific Journal of Human Resources, 46(3), 316-333.

Baum, S., Ma, J., \& Payea, K. (2010). Education pays 2010:The benefits of higher education for individuals and society. New York, NY: The College Board.

Beauregard, T. A., \& Henry, L. C. (2009). Making the link between work-life balance practices and organizational performance. Human Resource Management Review, 19(1), 9-22.

Berkowitz, P. (2003). The long haul. University Affairs, 2, 8-12.

Boeije, H. (2002). A purposeful approach to the constant comparative method in the analysis of qualitative interviews. Quality \& Quantity, 36, 391-409. 
Bourke, S., Holbrook, A., Lovat, T., \& Farley, P. (2004). Attrition, completion and completion times of $P h D$ candidates. Paper presented at the AARE Annual Conference, Melbourne.

Brus, C. P. (2006). Seeking balance in graduate school: A realistic expectation or a dangerous dilemma. New Directions for Student Services, 115, 31-45.

Byron, K. (2005). A meta-analytic review of work-family conflict and its antecedents. Journal of Vocational Behavior, 67, 169-198.

Charmaz, K. (2000). Grounded theory: Objectivist and constructivist methods. In N. K. Denzin \& Y. S. Lincoln (Eds.), Handbook of qualitative research (2nd ed.). Thousand Oaks, CA: Sage.

Council of Graduate Schools. (2008). Ph.D. completion and attrition: Analysis of baseline program data from the Ph.D. completion project. Washington, DC: Author.

Di Pierro, M. (2007). Excellence in doctoral education: Defining best practices. College Student Journal, 41(2), 368-375.

Drago, R., \& Kashian, R. (2003). Mapping the terrain of work/family journals. Journal of Family Issues, $24(4), 488-512$.

Gardner, S. K. (2009). Student and faculty attributions of attrition in high and low-competing doctoral programs in the United States. Higher Education, 58, 97-112.

Gardner, S. K., \& Gopaul, B. (2012). The part-time doctoral student experience. International Journal of Doctoral Studies. 7, 63-78. Retrieved from http://ijds.org/Volume7/IJDSv7p063-078Gardner352.pdf

Glaser, B. G. (1965). The constant comparative method of qualitative analysis. Social Problems, 12(4), 436-445.

Glaser, B. G., \& Strauss, A. L. (1967). The discovery of grounded theory: Strategies for qualitative research. Chicago, IL: Aldine.

Glesne, C. (2005). Becoming qualitative researchers: An introduction (3rd ed.). Boston, MA: Pearson.

Golde, C. M. (1998). Beginning graduate school: Explaining first-year doctoral attrition. New Directions for Higher Education, 101, 55-64.

Golde, C. M. (2000). Should I stay or should I go?: Student descriptions of the doctoral attrition process. Review of Higher Education, 23(2), 199-227.

Govendir, M., Ginns, P., Symons, R., \& Tammen, I. (2009). Improving the research higher degree experience at the Faculty of Veterinary Science, The University of Sydney. The Student Experience, Proceedings of the $32^{\text {nd }}$ HERDSA Annual Conference, Darwin, 6(9), 163-172.

Hadjioannou, X., Shelton, N.R., Fu, D, \& Dhanarattigannon, J. (2007). The road to a doctoral degree: Cotravelers through a perilous passage. College Student Journal, 41(1), 160-177.

Haynes, C., Bulosan, M., Citty, J., Grant-Harris, M., Hudson, J., \& Koro-Ljungberg, M., (2012). My world is not by doctoral program...or is it? Female students' perceptions of well-being. International Journal of Doctoral Studies, 7, 1-16. Retrieved from http://ijds.org/Volume7/IJDSv7p001-017Haynes329.pdf

Hobson, C. J., Delunas, L., \& Kesic, D. (2001). Compelling evidence of the need for corporate work/life balance initiatives: Results from a national survey of stressful life-events. Journal of Employment Counseling, 38, 38-44.

Jairam, D., \& Kahl, D. H. (2012). Navigating the doctoral experience: The role of social support in successful degree completion. International Journal of Doctoral Studies, 7, 311-328. Retrieved from http://ijds.org/Volume7/IJDSv7p311-329Jairam0369.pdf

Johnes, G., \& McNabb, R. (2004). Never give up on the good times: Student attrition in the UK. Oxford Bulletin of Economics and Statistics, 66(1), 23-47. 
Kamenou, N. (2008). Reconsidering work-life balance debates: Challenging limited understandings of the 'life' component in the context of ethnic minority women's experiences. British Journal of Management, 19, S99-S109.

Keeton, K., Fenner, D. E., Johnson, T. R. B., \& Hayward, R. A. (2007). Predictors of physician career satisfaction, work-life balance, and burnout. Obstetrics \& Gynecology, 109(4), 949-955.

Kluever, R. C. (1997). Students' attitudes toward the responsibilities and barriers in doctoral study. New Directions for Higher Education, 99, 47-56.

Lovitts, B. E. (2001). Leaving the ivory tower: The causes and consequences of departure from doctoral study. Lanham, MD: Rowman \& Littlefield.

Marshall, J. M., Brooks, J. S., Brown, K. M., Bussey, L. H., Fusarelli, B., Gooden, M. A., Lugg, C. A., Reed, L. C., \& Theoharis, G. (Eds.). (2012). Juggling flaming chain saws: Faculty in educational leadership try to balance work and family. Charlotte, NC: Information Age Publishing.

Mason, M. A., Goulden, M., \& Frasch, K. (2009). Why graduate students reject the fast track. Academe, $88,21-27$.

McAlpine, L., Jazvac-Martek, M., \& Hopwood, N. (2009). Doctoral student experience: Activities and difficulties influencing identity development. International Journal for Researcher Development, 1(1), 97-112.

McCoy, D.L \& Gardner, S. (2011). The transition from full-time employment to full-time graduate student: A qualitative exploration of master's and doctoral students' experiences in higher education programs. The Enrollment Management Journal, 5(1), 84-109.

Merriam, S.B. (1998). Qualitative research and case study applications in education. San Francisco: Jossey-Bass.

Morphew, C., \& Huisman, J. (2002). Using institutional theory to reframe research on academic drift. Higher Education in Europe, 27(4), 491-506.

Moyer, A., Salovey, P., \& Casey-Cannon, S. (1999). Challenges facing female doctoral students and recent graduates. Psychology of Women Quarterly, 23, 607-630.

O'Meara, K. A. (2007). Striving for what? Exploring the pursuit of prestige. In J. D. Smart (Ed.), Higher education: Handbook of theory and research, 22 (pp. 121-179). New York, New York: Springer.

Offerman, M. (2011). Profile of nontraditional doctoral degree students. New Directions for Adult and Continuing Education, 129, 21-30.

Offstein, E. H., Larson, M. B., McNeill, A. L., \& Mwale, H. M. (2004). Are we doing enough for today's graduate students? International Journal of Educational Management, 18(7), 396-407.

Patton, M. Q. (1990). Qualitative evaluation and research methods (2nd ed.). Newbury Park, CA: Sage.

Rosser, V. J. (2004). Faculty members' intention to leave: A national study on their worklife and satisfaction. Research in Higher Education, 45(3), 285-309.

Sallee, M. W. (2008). Work and family balance: How community college faculty cope. New Directions for Community Colleges, 142, 81-91.

Shulman, L. S., Golde, C. M., Bueschel, A. C., \& Garabedian, K. J. (2006). Reclaiming education's doctorates: A critique and a proposal. Educational Researcher, 35(3), 25-32.

Sipe, L. \& Constable, S. (1996). A chart of four paradigms: Metaphors for the modes of inquiry. Taboo: The Journal of Culture and Education, 1, 153-163.

Smallwood, S. (2004). Doctor dropout. The Chonicle of Higher Education. Available at http://chronicle.com/article/Doctor-Dropout/33786

Stimpson, R. L., \& Filer, K. L. (2011). Female graduate students' work-life balance and the student affairs professional. In P. A. Pasque, \& S. E. Nicholson (Eds.), Empowering women in higher education and 
student affairs: Theory, research, narratives, and practice from feminist perspectives (pp. 69-84). Sterling, VA: Stylus.

Walker, G. E., Golde, C. M., Jones, L., Bueschel, A. C., \& Hutchings, P. (2008). The formation of scholars: Rethinking doctoral education for the twenty-first century. San Francisco, CA: Jossey-Bass.

Watts, J. H. (2009). ‘Allowed into a man's world' meanings of work-life balance: Perspectives of women civil engineers as 'minority' workers in construction. Gender, Work, and Organization, 16(1), 37-57.

Weidman, J. C., \& Stein, E. L. (2003). Socialization of doctoral students to academic norms. Research in Higher Education, 44(6), 641-656.

Wendler, C., Bridgeman, B., Cline, F. Millett, C., Rock, J. Bell, N., McAllister, P. (2010). The path forward: The future of graduate education in the United States. Princeton, NJ: Educational Testing Service.

Wolcott, H. F. (1990). On seeking and rejecting validity in qualitative research. In E. Eisner \& A. Peshkin (Eds), Qualitative inquiry in education, (pp. 121-152). New York: Teachers College Press.

\section{Biographies}

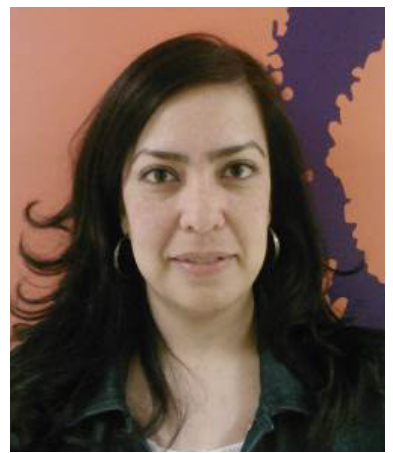

Edna Martinez is a doctoral candidate in Educational Leadership at Clemson University. Her research interests are centered on two strands of interrelated inquiry. The first attempts to explore organizational change at baccalaureate degree granting community colleges. She is particularly interested in understanding the kinds of organizational shifts in policies and practices that accompany the introduction of the community college baccalaureate. Drawing from the first strand, the second seeks to understand how modifications to existing policies and practices shape educational experiences and opportunities for traditionally underserved/underrepresented community college students.

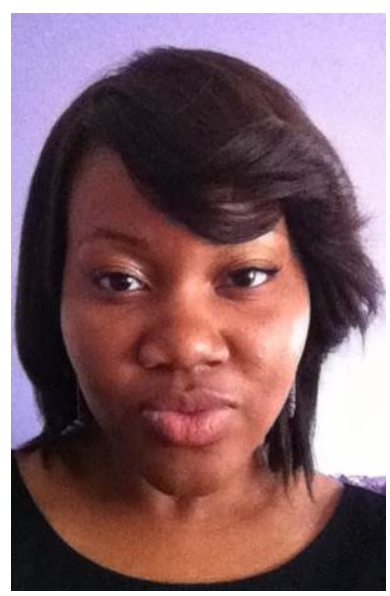

Chinasa Ordu is a doctoral candidate in the Educational Leadership program with a certificate in Policy Studies at Clemson University. Her dissertation research explores perceptions of increased debt on the college choice and enrollment of rural, low-income students. Her ongoing research focuses on access and equity for underserved students. 


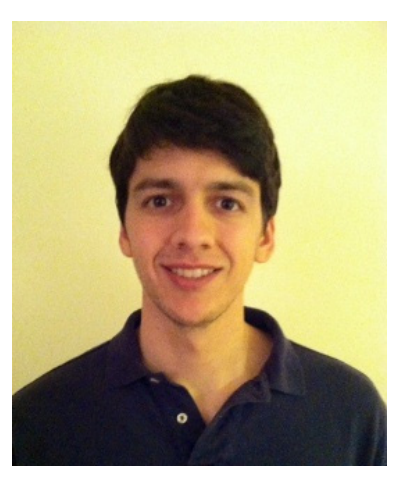

Matthew R. Della Sala is a second-year student in the $\mathrm{PhD}$ program in Educational Leadership at Clemson University. His research interests primarily include educational policy, finance, and the use of data in schools.

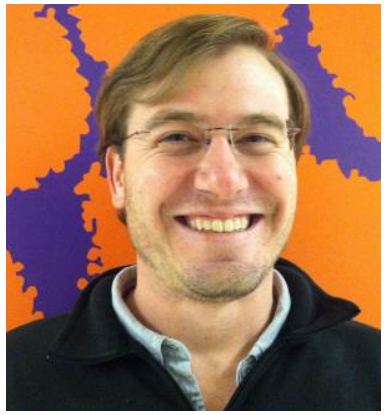

Adam McFarlane is currently a $\mathrm{PhD}$ student in the Educational Leadership - Higher Education - program at Clemson University. Stemming from his previous academic experience in sport management and work experience in college athletics departments, Adam's research interests primarily focus on leadership and policy within the athletic environment and its effects on the persistence and overall experiences of student athletes. Upon completing his degree, Adam plans to pursue a career in athletic administration, more specifically working alongside student athletes in their academic pursuits. 